\title{
REVISIÓN DEL GÉNERO DICHAPETALUM (DICHAPETALACEAE) EN COSTA RICA
}

\author{
Ricardo Kriebel \& AlexÁnder RodrígueZ
}

Instituto Nacional de Biodiversidad (INBio), apdo. 22-3100, Santo Domingo, Heredia, Costa Rica.

\begin{abstract}
A revision of the Costa Rican species of Dichapetalum (Dichapetalaceae) is presented here. Two new species, D. inopinatum and D. reliquum, are described and illustrated. Discussions, fenological notes and examined specimens are included for the 14 species present in Costa Rica.
\end{abstract}

Resumen. Se presenta una revisión del género Dichapetalum (Dichapetalaceae) en Costa Rica. Se describen e ilustran dos especies nuevas: $D$. inopinatum y $D$. reliquum. Se agregan notas fenológicas y especímenes examinados, además de discusiones sobre las 14 especies del país.

\section{Palabras clave / Kew words: Dichapetalaceae, Dichapetalum, Costa Rica}

El género Dichapetalum fue descrito de Madagascar por Du Petit Thouars en 1806 y es el género tipo de la familia Dichapetalaceae. Su nombre se deriva del griego dicha (dividido en dos) y petalon (pétalo), por los pétalos apicalmente bífidos de muchas de las especies (Prance 1972). Su distribución se extiende por los trópicos de todo el mundo y es el género más diverso de la familia en el neotrópico, con cerca de 26 especies. De éstas, más del 50\% (14 especies) están presentes en Costa Rica y hasta ahora cinco son endémicas.

La familia Dichapetalaceae fue monografiada por Prance (1972) en la región neotropical. Él reconoce 15 especies de Dichapetalum. Desde entonces se han publicado cerca de nueve especies más. El nombre de una de éstas (D. costaricense Prance) es, en realidad, sinónimo de D. axillare (Prance 1996). De las nuevas especies publicadas, tres habitan en Costa Rica y son endémicas aquí: $D$. grayumii Prance, $D$. hammelii Prance y D. moralesii Prance.

Con el fin de actualizar la taxonomía de Dichapetalum en Costa Rica, lo que incluye las dos especies nuevas aquí descritas, se presenta a continuación una revisión del género.
Dichapetalum Thouars, Gen. Nov. Madagasc. 23. 1806.

Árboles, arbustos o lianas con tallos glabros o pubescentes. Hojas simples, alternas, pecioladas, con nervadura pinnada, margen entero, envés con glándulas inconspicuas y esparcidas. Estípulas presentes, conspicuas o reducidas, persistentes o deciduas, enteras o fimbriadas. Inflorescencias cimosas o corimbosas, axilares, adnadas a los pecíolos o terminales. Flores pequeñas, hermafroditas, polígamas, dioicas $\mathrm{o}$ polígamo-dioicas, actinomorfas, sobre un pedicelo articulado cerca del ápice; sépalos 5, imbricados y externamente tomentulosos; pétalos 5, libres, bífidos. Estambres 5, iguales; filamentos libres. Disco con 5 glándulas (especies de Costa Rica), libres, enteras o lobadas, opuestas a los pétalos. Ovario tomentoso, bi o trilocular; estilos 1-3, libres o en parte connados. Fruto una drupa indehiscente, uni a trilocular, en ocasiones con uno o dos lóculos abortados.

Dichapetalum se distingue de los otros géneros neotropicales de la familia (Stephanopodium Poepp. y Tapura Aubl.) por sus pétalos libres, estambres igualmente libres e inflorescencias con pedúnculos generalmente evidentes. En los otros dos géneros los pétalos son connados o únicamente 3 son libres, los estambres están adnados a la corola y las inflorescencias son sésiles o casi sésiles.

\section{Clave de las especies costarricenses de Dichapetalum}

1 Estípulas con el margen fimbriado; siempre lianas

2 Envés de la lámina glabro, excepto por algunos tricomas adpresos sobre los nervios principales; frutos $c a$. 1.5$2.5 \times 1.3-2.8 \mathrm{~cm}$, tomentulosos externamente D. nervatum

2' Envés de la lámina densa a esparcidamente hirsuto; frutos 3-4.5 x 1.6-4 cm, híspidos externamente 
3 Ramitas terminales con tricomas entre (2-)2.5-3.5 mm; estípulas 10-30 mm; lámina foliar 16-31 x 8.5-15.5 $\mathrm{cm}$; estambres con filamentos 3.5-4 mm; centro y sur de la vertiente Pacífica......

3' Ramitas terminales con tricomas hasta $2 \mathrm{~mm}$; estípulas de 4-10 mm; lámina foliar (5-)9-22 cm x 2.3-8.5 $\mathrm{cm}$; estambres con filamentos hasta $2.25 \mathrm{~mm}$; vertiente Atlántica

4 Inflorescencia peciolar en hojas terminales; ramitas distales esparcidamente hirsutas con tricomas entre (1.25-)1.5-2 mm; envés de la lámina esparcidamente hirsuto sobre la nervadura; frutos elipsoides a oblongo-elipsoides. D. inopinatum

4' Inflorescencia axilar y terminal; ramitas distales densamente hirsutas con tricomas entre 0.25-1 mm; envés de la lámina densamente hirsuto; frutos globosos D. grayumii 1 'Estípulas con el margen entero; lianas, arbustos o árboles

5 Frutos externamente hirsutos a híspidos; haz de las hojas denso-hirsuto o esparcido-híspido

6 Planta arbustiva o árbol pequeño; tallos entremezclando esparcida pubescencia de tricomas largos (1-3 $\mathrm{mm}$ ) y erectos con tricomas reducidos e incurvos; estípulas persistentes; lámina foliar 1.5-4 cm de ancho, haz y envés esparcidamente híspidos, tricomas $1-2 \mathrm{~mm}$; vertiente Atlántica .................... D. nevermannianum 6' Planta trepadora (liana); tallos únicamente con densa pubescencia hirsuta, tricomas de 0.3-1.25 mm; estípulas deciduas, raras veces persistentes; lámina de $3-5.5 \mathrm{~cm}$ de ancho, haz y envés densamente hirsutos, tricomas de 0.5-1.5 mm; centro y sur de la vertiente Pacífica

D. reliquum 5' Frutos tomentulosos (o velutino-tomentosos en D. morenoi); haz de las hojas glabro, con tricomas restringidos a los nervios principales o, menos frecuente, también tomentuloso en la superficie en $D$. donnell-smithii pero nunca hirsuto o híspido

7 Plantas escandentes (lianas); ramificación divaricada o ascendente

8 Lámina de 6-12 cm de ancho, con el haz rugoso a abollado y envés de la lámina densamente hirsutotomentoso D. rugosum

8' Lámina de 2-7 cm de ancho, con el haz liso y el envés de la lámina glabro o pubescente solamente en hojas nuevas, en ocasiones algunos parches persistiendo en $D$. inopinatum, pero nunca cubriendo ni la mitad de la superficie

9 Tallos apicalmente glabros, conspicuamente lenticelados; eje de la inflorescencia lenticelado; fruto inmaduro obovado a obovado-elipsoide .................................................................... D. odoratum 9' Tallos apicalmente farinosos, con lenticelas ausentes o pocas esparcidas; eje de la inflorescencia sin lenticelas; fruto inmaduro fusiforme y conspicuamente arqueado apicalmente D. pedunculatum

7' Plantas arbóreas o arbustivas; ramificación ascendente, nunca divaricada

10 Envés de la lámina con la superficie glabra, en ocasiones la vena media y algunas venas secundarias estrigulosas a estrigosas

11 Inflorescencias siempre insertadas en los pecíolos; pedicelos en la antesis (2-)3-8 mm; > $1500 \mathrm{~m}$ de elevación D. brenesii 11' Inflorescencias axilares, excepcionalmemte alguna insertada en los pecíolos; pedicelos en la antesis $0.2-2.75 \mathrm{~mm} ;<1050 \mathrm{~m}$ de elevación

12 Láminas de 3.8-8.8 cm de ancho, elípticas, oblongo-elípticas, oblongo-obovadas, con la base obtusa, truncada o subcordada y el envés evidentemente estrigoso sobre la vena media; ramitas apicales tomentosas, tomentulosas, hirsutas o hirsútulas; bosques húmedos en la vertiente Caribe y el Pacífico Sur D. axillare 12' Lámina 1.2-3.1(3.5) cm de ancho, lanceoladas a oblongo-lanceoladas, con la base cuneada y el envés totalmente glabro o con pocos tricomas adpresos sobre la vena media; bosques secos y húmedos en la vertiente pacífica y norte de la vertiente Atlántica D. morenoi 10'Envés de la lámina esparcida a densamente hirsuto o denso-tomentoso sobre la venación y la superficie; tallitos jóvenes tomentulosos, tomentosos o esparcidamente hirsutos

13 Haz abollado; fruto de 2-4 x 1-2.5 cm, con 2 a 3 depresiones longitudinales, generalmente con 2 a 3 semillas al madurar; endocarpo liso D. rugosum

13' Haz liso; fruto de 1.5-2.5 x 1-1.5 cm, esencialmente terete, generalmente con una sola semilla al madurar; endocarpo leve a conspicuamente estriado

14 Estípulas de 3-15 mm, persistentes; vertiente Atlántica, $<600 \mathrm{~m}$ de elevación

D. moralesii

14' Estípulas de 2.5-5 mm, deciduas; vertiente Pacífica de la cordillera de Talamanca y sus estribaciones, $>1600 \mathrm{~m}$ de elevación D. donnell-smithii 
Dichapetalum axillare Woodson, Ann. Missouri Bot. Gard. 29: 353. 1942. Tipo. Panamá. Coclé: Valle de Antón; Allen 2202 (Holotipo: MO, isotipos: EAP, GH, NY, US). D. costaricense Prance, Kew Bull. 49(1): 129-131, f.1. 1993 [1994].

Arbusto o árbol pequeño, 2-7(-20) $\mathrm{m}$; tallitos medulosos, tomentosos, tomentulosos, hirsutos o hirsútulos. Estípulas: 3-12 mm, lineares a lineardeltoides, margen entero, persistentes, menos frecuente deciduas en nudos inferiores. Pecíolo de 2-7 $\mathrm{mm}$, con indumento similar al de los tallitos; láminas foliares 4-21.5 x 2.5-9 cm, elípticas, oblongo-elípticas, obovado-elípticas, cartáceas a subcoriáceas, base obtusa, truncada o subcordada, en ocasiones levemente asimétrica, ápice acuminado, 7-11 pares de venas secundarias, haz liso o apenas abollado, glabrado a esparcido-estriguloso sobre el nervio central, envés esparcido-estriguloso sobre la vena media y nervios secundarios, pero esencialmente glabra sobre la superficie. Inflorescencias 2.5-5 x 2.3-7.5 cm, terminales o axilares, excepcionalmente peciolares, ejes tomentulosos o al menos puberulentos; pedúnculos 4-20 mm, en ocasiones apenas diferenciables; brácteas y bracteolas $0.5-9 \mathrm{~mm}$, lanceoladas a linearlanceoladas; pedicelos $0.2-2 \mathrm{~mm}$ prolongándose hasta $3 \mathrm{~mm}$ en el fruto. Flores hermafroditas; sépalos 2-2.5 $\mathrm{mm}$; pétalos $1.75-2.5 \mathrm{~mm}$, bífidos, divididos entre 1/2-3/4 de su longitud; filamentos $1.25-2 \mathrm{~mm}$; anteras $0.4 \times 0.25 \mathrm{~mm}$. Glándulas del disco de 0.4-0.5 x 0.3$0.5 \mathrm{~mm}$, obovadas, diminutamente lobadas. Ovario bi o trilocular, sobre un estípite $c a .0 .5 \mathrm{~mm}$, aunque en ocasiones no diferenciado; estilos 3, 0.5-1.25 mm, unidos por $1 / 2-2 / 3$ de su longitud, frecuentemente libres hasta la base. Fruto 1-1.5 x 0.6-1.4 cm, uni a trilocular, elipsoide a obovado, epicarpo pardo a café tomentuloso, tricomas reducidos, rígidos, base redonda a levemente cuneada, aunque manteniendo una sola semilla al madurar, mesocarpo 1-2 $\mathrm{mm}$ de grosor, endocarpo leñoso, liso.

Distribución. Costa Rica, Panamá y norte de Colombia. En Costa Rica la encontramos en los bosques muy húmedos de la vertiente caribe en las llanuras de Tortuguero (Estación Biológica La Selva) y llanuras de San Carlos, en la vertiente pacífica en la Península de Osa; y en la Cordillera de Tilarán en ambas vertientes, 50 a $900 \mathrm{~m}$ de elevación.

Fenología. Flores de abril a setiembre; frutos en enero y junio.

Esta especie es variable en tamaño de las hojas, estípulas, densidad de indumento, así como en tamaño de los estilos. Especímenes provenientes de la Cordillera de Tilarán, con hojas y estípulas de mayor tamaño, fueron descritos como Dichapetalum costaricense por Prance (1994); posteriormente, el mismo autor (Prance 1996) relegó este nombre a sinónimo. Prance (1972) describe las estípulas de esta especie como deciduas, pero el material costarricense examinado tiene estípulas persistentes y conspicuas, sólo raras veces deciduas.

Dichapetalum axillare se relaciona con $D$. brenesii Standl. Este nombre fue considerado sinónimo del primero por Prance (1972), quien luego reconoció que efectivamente son especies diferentes (Prance 1996). Ambas se distinguen por el origen de las inflorescencias, ya que en esta última son terminales y peciolares; además, los pecíolos son más largos, la lámina foliar glabra o inconspicuamente serícea sobre la vena media en el envés, y finalmente debido a que $D$. brenesii crece a mayores elevaciones. $D$. axillare también se compara con $D$. donnell-smithii, la cual se distingue por las inflorescencias generalmente peciolares, terminales y menos frecuente axilares, la lámina foliar oblongo-elíptica a elíptica y densotomentosa en el envés y porque crece sobre $1700 \mathrm{~m}$ de elevación. Ver la clave y los comentarios sobre $D$. moralesii, para comparar con esta especie.

Especímenes examinados. Costa Rica. Alajuela: Guatuso, $5 \mathrm{~km} \mathrm{~N}$ del Lago Arenal, cercanías del Lago Cote, sendero Zamia, $10^{\circ} 35^{\prime} \mathrm{N}, 84^{\circ} 55^{\prime} \mathrm{W}, 800$ 1000 m, 15 ago 1996, J. Sánchez 714 (CR); Guatuso, P. N. Volcán Tenorio, cuenca del Río Frío, El Pilón, $10^{\circ} 42^{\prime} \mathrm{N}, 84^{\circ} 59^{\prime} \mathrm{W}, 800 \mathrm{~m}, 8$ jun 2000 , J.L. Chaves 432 (CR, INB, MO); San Ramón, P.N. Arenal, cuenca del San Carlos, sendero al Cerro Chato, entrando por Arenal Lodge, $10^{\circ} 25^{\prime} \mathrm{N}, 84^{\circ} 41^{\prime} \mathrm{W}, 900$ $\mathrm{m}$, A. Rodríguez et al. 5032 (CR, INB, MO); Reserva Biológica de Monteverde, Río Peñas Blancas, campo $3,10^{\circ} 20^{\prime} \mathrm{N}, 84^{\circ} 42^{\prime} \mathrm{W}, 900 \mathrm{~m}, 26$ jun 1989, E. Bello 1523 (CR, INB). Heredia: Sarapiquí, Puerto Viejo, Finca La Selva, primary forest along the Stiles trail, near Quebrada El Salto, $10^{\circ} 26^{\prime} \mathrm{N}, 84^{\circ} 01^{\prime} \mathrm{W}, 8$ Aug 1973, G. Hartshorn 1270 (CR); Sarapiquí, Puerto Viejo, Finca La Selva, 90 m, 4 ago 1971, Opler 330; Sarapiquí, Puerto Viejo, $3 \mathrm{~km}$ SE of Puerto Viejo, 45 m, 6 ago 1972, Opler 984; $10 \mathrm{~km}$ down the road, then $7-8 \mathrm{~km}$ west in forest north of Puerto Viejo, Sarapiquí, 2 Febr 1983, Garwood et al. 873; Sarapiquí, Rara Avis, ca. $15 \mathrm{~km}$ al suroeste de Horquetas, $10^{\circ} 17^{\prime} \mathrm{N}$, $84^{\circ} 02^{\prime} \mathrm{W}, 400-600 \mathrm{~m}, 8$ nov 1989, O. Vargas 289. Limón: Cerro Coronel, E of Laguna Danto, $10^{\circ} 41^{\prime} \mathrm{N}$, 
833' W, 20-170 m, 16-23 ene 1986, W.D. Stevens 23880 (CR, MO). Puntarenas: Cantón de Golfito, Reserva Forestal de Golfito, serranías de Golfito, cerros detrás de Esquinas Rainforest Lodge, entre Villa Briceña y Golfito, $8^{\circ} 42^{\prime} \mathrm{N}, 83^{\circ} 12^{\prime} \mathrm{W}, 200-300$ m, 12 sept 1996, B. Hammel et al. 20489 (CR, INB, MO); Cantón de Osa, Agua Buena, Rincón, sector del tanque de agua del pueblo, al norte de Boscosa, $8^{\circ} 42^{\prime} \mathrm{N}, 83^{\circ} 31^{\prime} \mathrm{W}, 75-150 \mathrm{~m}, 3$ sept 1990, C. Morales 129 (CR, INB, MO); Cantón de Osa, Reserva Forestal Golfo Dulce, Península de Osa, camino a Rancho Quemado, sitio conocido como Baneguitas, en la cuenca de la Quebrada Banegas, 8 $41^{\prime} \mathrm{N}, 83^{\circ} 32^{\prime} \mathrm{W}$, 200 m, 13 ene 1993, B. Hammel et al. 18726 (CR, INB, MO); Cantón de Osa, Rancho Quemado, sector oeste, Sierpe, $8^{\circ} 40^{\prime} \mathrm{N}, 83^{\circ} 35^{\prime} \mathrm{W}, 250$ m, 16 ago 1992 , J. Marín 492 (CR, INB, MO).

Dichapetalum brenesii Standl., Publ. Field Mus. Bot. 23: 13. 1943. Tipo. Costa Rica. Alajuela: Zarcero; Austin Smith 4120 (Holotipo: F, isotipos: CR, EAP, $\mathrm{UC})$.

Arbusto o árbol pequeño, 2-6 m; tallitos medulosos, ramitas jóvenes estrigoso-puberulentas, con tricomas entre 0.1-0.75 mm. Estípulas 3-6 mm, lineares o linearlanceoladas, margen entero, tempranamente deciduas. Pecíolo de 4-17 mm, esparcido-seríceo, especialmente en la superficie adaxial; láminas foliares 7-21 x 2.8-7.3 $\mathrm{cm}$, elípticas, oblongo-elípticas a obovado-elípticas, cartáceas a subcoriáceas, base cuneada a obtusa, ápice acuminado, 7-11 pares de venas secundarias, haz liso, glabro, envés glabro a esparcido-seríceo sobre el nervio central, especialmente hacia la base, en ocasiones también seríceo en algunos nervios secundarios. Inflorescencias 2.7-6.5 x 1.9-6 cm, peciolares y terminales, ejes seríceo-tomentulosos; pedúnculos 4-19 mm; brácteas y bracteolas 0.5-4 $\mathrm{mm}$, lanceoladas a linear-lanceoladas; pedicelos 2$8 \mathrm{~mm}$. Flores hermafroditas; sépalos 2.5-2.75 mm; pétalos 2-2.5 mm, divididos hasta $c a$. $1 / 4$ de su longitud; filamentos 1.75-2.25 mm; anteras 0.5-0.6 x 0.3-0.4 mm. Glándulas del disco de 0.4-0.5 x 0.25$0.35 \mathrm{~mm}$, obovadas a casi clavadas, diminutamente lobadas. Ovario bilocular sobre un estípite de 0.25 $0.35 \mathrm{~mm}$; estilos 2, 0.25-0.35 mm, esparcido-lanados, generalmente libres casi hasta la base. Fruto inmaduro, ca. $1.5 \times 0.8 \mathrm{~cm}$, bilocular, ovoide-elíptico, epicarpo pardo-tomentuloso, base cuneada o atenuada, sobre un estípite de $0.75-1 \mathrm{~mm}$.

Distribución. Belice y Costa Rica. En Costa Rica la encontramos en los bosques pluviales de las cordilleras de Tilarán, Central y de Talamanca, en ambas vertientes, 1500-2260 m de elevación.

Fenología. Flores de marzo a octubre; frutos en enero.

En Flora Neotropica (Prance 1972) esta especie fue tratada como sinónimo de $D$. axillare, una especie relacionada pero que se distingue por sus inflorescencias axilares, flores con el ovario bi o trilocular, 2-3 estilos, los cuales son más alargados y unidos, frutos ovoides e igualmente bi o triloculares $\mathrm{y}$ debido a que es una especie frecuente a menor elevación. También, ver la clave y los comentarios sobre D. pedunculatum, para comparar con esta especie.

Un carácter vegetativo de $D$. brenesii, que comparte con pocas especies del género, son los 2-4 dientes diminutos en la superficie adaxial del pecíolo, aunque a menudo no distinguibles en material de herbario. Esta especie llega a ser común en elevaciones medias.

Especímenes examinados. Costa Rica. Alajuela: Reserva Biológica de Monteverde, entre sendero pantanoso y Río Peñas Blancas, 1200-1400 m, 13 jun 1985, Haber \& Bello 1638 (CR). Cartago: Pejiballe, Jiménez, Finca La Margarita, 1100 m, 24 mar 1986, Q. Jiménez 295 (CR); Orosi, 8 km SE of Tapantí, 1500 m, 18 Jun 1967, R.W. Lent 1052 (CR); P.N.Tapantí Macizo de la Muerte, cuenca del Reventazón, $1 \mathrm{~km}$ después del portón hacia Río Humo, sobre sendero a las torres, $9^{\circ} 43^{\prime} \mathrm{N}, 83^{\circ} 46^{\prime} \mathrm{W}, 1500 \mathrm{~m}, 22$ mar 2000, $L$. Acosta \& V. Ramírez 672 (CR, INB, MO); Orosi, Kiri Lodge, Sendero Colibrí, 946’N, 834ㄱ'W, $1200 \mathrm{~m}$, R. Kriebel \& D. Solano 3656 (CR, INB). Heredia: Cantón de Barva, P.N. Braulio Carrillo, Porrosatí, finca alrededores de Río Ciruelas, $10^{\circ} 05^{\prime} \mathrm{N}, 84^{\circ} 06^{\prime} \mathrm{W}$, 1900 m, 26 mayo 1990, G. Rivera 379 (CR, INB, MO); Quebrada Machete, borde Cerro Zurquí, 12 febr 1984, L.D. Gómez 21022 et al. (CR); San Luis, Hacienda Santa Fé, 7 jul 1975, L.J. Poveda s.n. (CR); remnant woods between Paró Blanco (?) and Bajo La Hondura, $10^{\circ} 03^{\prime} \mathrm{N}, 84^{\circ} 01^{\prime} \mathrm{W}, 1660 \mathrm{~m}, 22$ oct 1972 , R.W. Lent 3019 (CR); Vara Blanca, Poasito, 4 ago 1951, $2200 \mathrm{~m}$, J. León 3705 (CR); Puntarenas: Reserva Biológica de Monteverde, cerca de división continental, 15201580 m, 21 jul 1976, V.J. Dryer 300 (CR); R.B. de Monteverde, Ojo de Agua, Finca de Alvarado, lado pacífico, $10^{\circ} 15^{\prime} \mathrm{N}, 84^{\circ} 46^{\prime} \mathrm{W}, 1600 \mathrm{~m}, 17$ nov 1987 , Haber \& Bello 7771 (CR, MO); R.B. de Monteverde, road to TV towers on Cerro Amigos, lower montane rain forest, $10^{\circ} 18^{\prime} \mathrm{N}, 84^{\circ} 48^{\prime} \mathrm{W}, 1700-1750 \mathrm{~m}$, Haber 
\& Zuchowski 11461 (CR, INB, MO).

Dichapetalum donnell-smithii Engl., Bot. Jahrb. 23: 144. 1924. Tipo. Guatemala. Escuintla; J. D. Smith 2067 (Holotipo: B, isotipos: G, GH, K, M, NY, P, US).

Árbol de 5-12 m; tallitos medulosos, tomentulosos a velutino-tomentosos, al menos en ramitas terminales. Estípulas 2.5-5 mm, deltoides, margen entero, deciduas (incluso raras veces visibles en nudos superiores). Pecíolo de 4-15 mm, con indumento similar al de los tallitos; lámina foliar 3-17 x $1.5-7 \mathrm{~cm}$, elípticas, oblongo-elípticas, cartáceas a subcoriáceas, base cuneada, menos frecuente obtusa, ápice acuminado, 6-12 pares de venas secundarias, haz liso, esparcidopubescente a glabrado, envés densamente hirsutotomentoso. Inflorescencias $0.5-6$ x $0.75-3 \mathrm{~cm}$, peciolares y terminales o axilares, ejes tomentulosos a velutino-tomentosos; pedúnculo $2-13 \mathrm{~mm}$, a menudo no claramente diferenciado; brácteas y bracteolas 1.5-3 $\mathrm{mm}$, deltoides; pedicelos 1-3 mm. Flores hermafroditas; sépalos 2-2.5 $\mathrm{mm}$; pétalos 2-2.5 $\mathrm{mm}$, bífidos, divididos entre $c a$. 1/4-1/2 de su longitud; filamentos $2-2.75 \mathrm{~mm}$; anteras $0.55 \times 0.25 \mathrm{~mm}$. Glándulas del disco de 0.4$0.5 \times 0.1-0.25 \mathrm{~mm}$, obovadas, diminutamente lobadas. Ovario bilocular, sobre un estípite de 0.6-1.25 mm; estilos 2, ca. $0.25 \mathrm{~mm}$ o menos, unidos la mayor parte de su longitud. Fruto 2-2.5 x 1-1.5 cm, uni o bilocular, ovoide a ovoide-obovado, epicarpo pardo tomentuloso, base levemente cuneada, generalmente abortando un lóculo y manteniendo únicamente una semilla al madurar, mesocarpo $0.5-1 \mathrm{~mm}$ de grosor, endocarpo débilmente estriado.

Distribución. Sur de México a Colombia. En Costa Rica la encontramos en los bosques pluviales de la vertiente pacífica de la Cordillera de Talamanca y sus estribaciones (Cerros de Caraigres y Escazú), 1700$2300 \mathrm{~m}$ de elevación.

Fenología. Flores y frutos de abril a setiembre.

Esta especie se encuentra estrechamente relacionada con $D$. moralesii (ver clave y comentarios sobre esta última). También es muy afín a $D$. axillare por hábito, similitud vegetativa, floral y de frutos; sin embargo, se distinguen debido a que esta última generalmente tiene inflorescencias axilares o terminales (raras veces peciolares), hojas con la pubescencia restringida a la venación, estípulas que llegan a ser más largas y persistentes, flores con 3 estilos, los cuales son más alargados, ovario con estípite más corto, mesocarpo de los frutos más engrosado y leñoso y se halla a menor elevación.

En Flora Neotropica (Prance 1972), el autor describe esta especie también con hábito escandente, hojas glabradas y con la base en ocasiones subcordada. En esta revisión, basados en ejemplares de los herbarios CR e INB, además del trabajo de campo realizado, consideramos esta especie estrictamente arborescente, con hojas no subcordadas y siempre con denso indumento en ramitas y envés de la lámina. Material de herbario referido a esta especie por Prance (loc. cit.) (Burger \& Liesner 6765, CR) podría corresponder mejor a $D$. odoratum, un taxon con hábito escandente y otras diferencias importantes (ver comentarios sobre esta última). Es probable que la interpretación presentada por Prance se derive de dichas identificaciones. También, el mismo autor reconoce dos variedades de la especie (Prance 1972): var. chiapensis y var. donnellsmithii. Nuestro material se ajusta mejor a la segunda entidad. Sin embargo, es importante considerar que dicha variedad es descrita por el autor con estípulas que llegan a ser más largas (hasta de $25 \mathrm{~mm}$ ) y hojas más anchas (hasta $13 \mathrm{~cm}$ ). A la vez, la descripción de la especie indica flores con 3 estilos, mientras que en nuestro material se han observado 2 estilos. En el resto de caracteres diagnósticos, nuestro material se ajusta satisfactoriamente con $D$. donnell-smithii var. donnellsmithii.

Especímenes examinados. Costa Rica. San José: Acosta, Zona Protectora Cerros de Caraigres, Cerro Caraigres, bosque primario en Fila El Alto, cerca de la gruta, $9^{\circ} 42^{`} \mathrm{~N}, 84^{\circ} 06^{\circ} \mathrm{W}, 2100-2300 \mathrm{~m}, 16$ abr 1994, J.F. Morales \& R.J. Abarca 2681 (CR, INB, MO); Escazú, Cerros de Escazú / La Carpintera, bosques secundarios riparios en el sendero del Río Lajas, $9^{\circ} 51^{\circ} \mathrm{N}, 84^{\circ} 07^{\circ} \mathrm{W}$, $1700 \mathrm{~m}, 5$ ago 1995, J.F. Morales 4625 (CR, INB, MO); Cerros de Escazú, Salvaje, bosque poco alterado al lado del camino, 2100 m, 15-16 jun 2003, R. Kriebel et al. 3243 (CR, INB, MO); Cerros de Escazú, Salvaje, bosque ripario poco alterado, $2100 \mathrm{~m}, 8-9$ sept 2003, R. Kriebel et al. 3782 (CR, INB, MO). Puntarenas: Buenos Aires, siguiendo el camino entre Sipar y Olán, cuenca superior del Río Cabagra, $9^{\circ} 17^{\circ} \mathrm{N}, 83^{\circ} 13^{\circ} \mathrm{W}$, 1700 m, 23 sept 1989, G. Herrera 3535 (CR, INB, MO); Coto Brus, P.N. La Amistad, cuenca TérrabaSierpe, estación Pittier, base del Cerro Pittier, $9^{\circ} 02^{`} \mathrm{~N}$, $82^{\circ} 57^{\circ} \mathrm{W}, 1800 \mathrm{~m}, 26$ abr 1998, N. Zamora et al. 2700 (CR, INB).

Dichapetalum grayumii Prance, Kew Bull. 49: 131. 1994. Tipo. Costa Rica. Limón: Cerro Coronel, este del Río Zapote; Stevens, Herrera \& Montiel 24695 
(Holotipo: $\mathrm{K}$, isotipo: $\mathrm{MO}$ ).

Lianas; tallitos medulosos, denso-hirsutos con tricomas de 0.25-1.1 mm; estípulas 4-8 mm, lanceoladas, con el margen fimbriado (en apariencia pinnatífidas), persistentes, menos frecuente deciduas. Pecíolos de 2-5 mm, hirsutos; lámina foliar (5-)9$22 \times(2.3-) 3.5-8.2 \mathrm{~cm}$, elíptica, oblongo-elíptica a obovado-elíptica, cartácea, base obtusa o subcordada, con frecuencia desigual, ápice acuminado, 7-11 pares de venas secundarias, haz levemente abollado, esparcido-pubescente, principalmente sobre los nervios principales, envés denso-hirsuto con tricomas de 0.25-1 mm. Inflorescencias $1-4 \mathrm{~cm} \times$ 1.3-5 cm, axilares, ejes denso-tomentosos a densohirsutos; pedúnculos 3-23 mm, en ocasiones apenas diferenciables; brácteas y bracteolas 3-6 mm, linearsubuladas; pedicelos 2-4 mm. Flores hermafroditas; sépalos 2-3 $\mathrm{mm}$; pétalos $2.5-3 \mathrm{~mm}$, divididos hasta ca. 3/4 partes de su tamaño; filamentos $1.75-2.25 \mathrm{~mm}$; anteras 0.35-0.45 x 0.2-0.3 mm. Glándulas del disco de $0.4-0.5 \times 0.25 \mathrm{~mm}$, obovadas, levemente lobadas. Ovario bi o trilocular sobre un estípite de 0.4-0.6 $\mathrm{mm}$; estilos 2-3, 0.75-1 mm, unidos hasta $3 / 4$ de su longitud, a veces libres hasta la base. Fruto hasta $4 \mathrm{x}$ $4 \mathrm{~cm}$, bi o trilocular, globoso, epicarpo densamente pardo-híspido, tricomas 2-4 $\mathrm{mm}$, rígidos, base obtusa, con frecuencia abortando uno o dos loculos y manteniendo sólo una semilla al madurar, mesocarpo 3-5 mm de grosor, endocarpo irregularmente leñoso, acostillado.

Distribución. Nicaragua y Costa Rica. En Costa Rica la encontramos en los bosques húmedos y muy húmedos de la vertiente caribe, en las llanuras de Tortuguero, llanuras de San Carlos y en la Cordillera de Guanacaste, 60-700 m de elevación.

Fenología. Flores en mayo, julio y noviembre; frutos entre mayo y junio.

Dichapetalum grayumii es similar a $D$. nervatum por el hábito escandente y las estípulas fimbriadas; además, ambas especies podrían ser simpátricas. Se distinguen ya que esta última tiene el envés de las hojas glabrado (excepto en nervios principales) y los pecíolos de mayor tamano. Con material fértil son fácilmente diferenciables ya que $D$. nervatum presenta inflorescencias terminales o peciolares y el exterior del fruto es tomentuloso. D. grayumii también se encuentra estrechamente relacionada con $D$. bullatum Standl. \& Steyerm., de Guatemala y Nicaragua, y $D$. gentryi Prance, de Panamá, de las cuales se separa principalmente (al menos hasta ahora) por caracteres vegetativos, como tamaño y textura de la lámina. Ver comentarios sobre D. hammelii Prance, para comparar con esta especie.

Especímenes examinados. Costa Rica. Alajuela: San Carlos, cuenca del San Carlos, ca. 7 km NE de Boca Tapada, Lagarto Lodge, $10^{\circ} 41^{\circ} \mathrm{N}, 84^{\circ} 10^{\circ} \mathrm{W}, 90 \mathrm{~m}, 27$ jul 1996, B. Hammel 20349 (CR, INB); San Carlos, Llanura de San Carlos, Proyecto Minero PlacerDome, camino al Cerro Crucitas, $10^{\circ} 52^{\circ} \mathrm{N}, 84^{\circ} 18^{\prime} \mathrm{W}$, 100-200 m, 25 jul 1996, J. González et al. 1128 (CR, INB). Guanacaste: P.N. Guanacaste, Estación Pitilla, $10^{\circ} 00^{\circ} \mathrm{N}, 85^{\circ} 25^{\circ} \mathrm{W}, 500 \mathrm{~m}, 27$ mayo 1989, G. Herrera 2944 (CR, INB, MO); P.N. Guanacaste, Estación Pitilla, $9 \mathrm{~km}$ al S de Santa Cecilia, La Cruz, $10^{\circ} 59^{\circ} \mathrm{N}$, $85^{\circ} 25^{\circ} \mathrm{W}, 700 \mathrm{~m}, 21$ mayo 1990, I INBio 203 (CR, INB, MO); P.N. Guanacaste, Estación Pitilla, Senderos Nacho y Laguna, 550 m, 15 jun 1989, III INBio 24 (CR, INB, MO). Heredia: Sarapiquí, Llanura de San Carlos, Finca Bejuco, remanentes de bosque primario en cerros Sardinal, $10^{\circ} 27^{\circ} \mathrm{N}, 84^{\circ} 04^{\circ} \mathrm{W}, 60 \mathrm{~m}, 23$ nov 1994, J.F. Morales et al. 3213 (INB); Sarapiquí, Chilamate, Finca El Bejuco, at southern end of Cerros sardinal (N of Río Sarapiquí), $10^{\circ} 27^{\circ} \mathrm{N}, 84^{\circ} 04^{\circ} \mathrm{W}, c a$. 100 m, 14 Dec 1984, M. Grayum et al. 4623 (CR, MO). Limón: Cerro Coronel, E of Río Zapote, along and above new road within $1 \mathrm{~km}$ of Río Colorado, $10^{\circ} 40^{\prime} \mathrm{N}, 83^{\circ} 40^{\prime} \mathrm{W}, 10-40 \mathrm{~m}, 13-14$ Sept 1986, W.D. Stevens 24332 (CR, MO).

Dichapetalum hammelii Prance, Kew Bull. 49: 133. 1994. Tipo. Costa Rica. Puntarenas: Reserva Forestal Golfo Dulce, Península de Osa, Rancho Quemado, Hammel, Herrera, Chavarría \& Solís 16878 (Holotipo: $\mathrm{K}$, isotipos: $\mathrm{CR}, \mathrm{INB}, \mathrm{MO}$ ).

Lianas; tallos con frecuencia fistulosos (al menos en partes inferiores), densamente híspido-hirsutos, tricomas 2.5-3.5 mm. Estípulas 10-30 mm, fimbriadas (en apariencia pinnatífidas), persistentes. Pecíolos de 3-10 mm, híspido-hirsutos; láminas foliares 16-31 x $8.5-15.5 \mathrm{~cm}$, elíptico-ovadas a oblongo-obovadas, cartáceas, base obtusa, subtruncada, cuneada a menos frecuente asimétrica, ápice acuminado, 7-12 pares de venas secundarias, haz liso, no abollado, aunque venas con frecuencia conspicuas, esparcido-pubescente a densamente viloso o hirsuto sobre los nervios principales, envés hirsuto, especialmente sobre los nervios principales. Inflorescencias 4-7 x $3.5-6 \mathrm{~cm}$, axilares o terminales, ejes denso-híspidos; pedúnculos 9-40 $\mathrm{mm}$; brácteas y bracteolas $4-10 \mathrm{~mm}$, linear- 
subuladas; pedicelos 1-3 mm. Flores hermafroditas; sépalos 2.5-3.25 mm; pétalos 2.75-3.5 mm, divididos hasta $c a .3 / 4$ partes de su longitud; filamentos $3.5-4 \mathrm{~mm}$; anteras 0.45-0.6 x 0.3-0.4 mm. Glándulas del disco de 0.35-0.5 x $0.4 \mathrm{~mm}$, obovadas a más o menos clavadas, obtusas en el ápice. Ovario bi a trilocular, sobre un estipite de 0.5-0.6 mm; estilos 2-3, 1-1.75 mm, unidos ca. 3/4 de su longitud, a veces libres hasta la base. Fruto $3.5-4.5 \times 2.3-3.2 \mathrm{~cm}$, bi o trilocular, oblongoobovado a oblongo-elipsoide, con 2-3 depresiones longitudinales, aunque cuando juveniles globosos, sin depresiones marcadas, epicarpo densamente pardo híspido, tricomas de $1.5-3 \mathrm{~mm}$, rígidos, base obtusa a subtruncada, generalmente abortando uno o dos lóculos y manteniendo sólo una o dos semillas al madurar, mesocarpo $c a .3 \mathrm{~mm}$ de grosor, endocarpo no leñoso, estriado.

Distribución. Endémica en la vertiente Pacífica de Costa Rica, en bosques húmedos y muy húmedos desde el Parque Nacional La Cangreja hasta la Península de Osa, 1-450 m de elevación.

Fenología. Flores entre abril y mayo; frutos en mayo y agosto.

Dichapetalum hammelii se distingue de las otras especies del género presentes en Costa Rica por sus grandes y persistentes estípulas fimbriadas, hojas igualmente más grandes y flores con estambres alargados; además, se caracteriza por su hábito trepador, tallos con frecuencia fistulosos, ramitas y lámina foliar híspido-hirsutas, frutos híspidos, bi o triloculares, con 2-3 depresiones longitudinales, al menos cuando maduros y por ser una especie restringida a la vertiente pacífica de Costa Rica.

Se encuentra estrechamente relacionada con $D$. grayumii por hábito, forma de estípulas y pubescencia; sin embargo, esta especie posee hojas y estípulas más pequeñas; estas últimas menos divididas, estambres más cortos y frutos globosos sin depresiones longitudinales. También, ver la clave y los comentarios sobre $D$. inopinatum, para comparar con esta especie.

Por otro lado, $D$. hammelii también es similar a $D$. bullatum Standl. \& Steyerm. (Guatemala, Honduras y dudosamente Nicaragua), pero esta última posee hojas abolladas, coriáceas, y estípulas más pequeñas. El fruto de $D$. bullatum se desconoce, razón por la cual posteriores recolectas con frutos podrán aportar mayor información sobre ambas especies.

Especímenes examinados. Costa Rica. Puntarenas: Golfito, Estación Esquinas, $8^{\circ} 46^{\prime} \mathrm{N}, 8^{\circ} 15^{\circ} \mathrm{W}, 100 \mathrm{~m}$,
25 ago 1993, M. Segura \& F. Quesada 150 (CR, INB, MO); Osa, Golfo Dulce interno, Fila Casa Loma, Cerro Chocuaco, $8^{\circ} 42^{\prime} \mathrm{N}, 8^{\circ} 29^{\prime} \mathrm{W}, 0 \mathrm{~m}($ ?), 15 abr 1998, $R$. Aguilar 5414 (CR, INB, MO); Reserva Forestal Golfo Dulce, Península de Osa, Rancho Quemado, ca. 15 $\mathrm{km}$ W of Rincón, on forested slopes at NW end of valley, near Fila Ganado, $8^{\circ} 33^{\prime} \mathrm{N}, 83^{\circ} 35^{\prime} \mathrm{W}, 300-400$ m, 29 May 1988, B. Hammel et al. 16878 (CR, INB, K, MO). San José: Puriscal, Z.P. La Cangreja, Cerros de Puriscal, Río Negro, fila innominada al sur del río desde el puente, $9^{\circ} 40^{\prime} \mathrm{N}, 84^{\circ} 23^{\prime} \mathrm{W}, 290-350 \mathrm{~m}, 18$ ago 1996, J.F. Morales 5719 (CR, INB, MO); Carara National Park, edge of park near Río del Sur, foothills of Montañas de Jamaica, $9^{\circ} 45^{\prime} \mathrm{N}, 83^{\circ} 32^{\prime} \mathrm{W}, 150-400 \mathrm{~m}$, 3 Apr 1993, A. Gentry et al. 79358 (CR, INB, MO).

\section{Dichapetalum inopinatum Al. Rodr. \& Kriebel, sp.} nova

Tipo: Costa Rica. Limón; Parque Nacional Tortuguero, sendero detrás de Tortuguero Lodge, 8 febr 1986; $R$. Soto s.n. (Holotipo: CR-11699).

Fig. 1

Dichapetalo hammelii Prance proxima, sed ramulis sparse hirsutis, foliis minoribus, subtus sparse hirsutis, stipulis minoribus, inflorescentiis semper e petiolis productis differt; a D. grayumii Prance affinis, sed foliis subtus sparse hirsutis, inflorescentiis semper e petiolis productis, fructibus ellipsoidibus vel oblongoellipsoidibus dignoscenda; D. bullato Standl. similis, sed foliis minoribus, chartaceis, subtus sparse hirsutis, non bullatis, divergens.

Lianas; tallitos medulosos, esparcido-hirsutos con tricomas de 1.5-2 mm. Estípulas 6-12 mm, con el margen fimbriado (en apariencia pinnatífidas), persistentes a deciduas en nudos inferiores. Pecíolos de 3-7 mm, hirsutos, láminas foliares $4.5-20 \times 2-8.5 \mathrm{~cm}$, obovadas, cartáceas, base obtusa a subcordada, ápice corto-acuminado, 9-14 pares de venas secundarias, haz liso, glabro o con indumento inconspicuo sobre la vena media, especialmente hacia la base, envés esparcido-hirsuto sobre la venación, tricomas 0.5-1.5 $\mathrm{mm}$, glabrado con la edad. Inflorescencias $c a .5 \times 8$ $\mathrm{cm}$, peciolares o terminales, ejes hirsutos; pedúnculos 0.4-1 cm; brácteas y bracteolas $1.5-7 \mathrm{~mm}$, lineares; pedicelos 1-3 mm (en fruto). Flores con sépalos 2.5$3 \mathrm{~mm}$; pétalos $c a .2 .5 \mathrm{~mm}$, divididos $c a .1 / 2$ de su longitud; filamentos $1.25-1.5 \mathrm{~mm}$; anteras $c a .0 .5 \times 0.3$ $\mathrm{mm}$. Glándulas del disco $0.25-0.35 \mathrm{~mm} \times 0.25 \mathrm{~mm}$, oblongo-obovadas, diminutamente lobadas; estilos (2) 3, ca. $2.5 \mathrm{~mm}$, connados ca. $4 / 5$ de su longitud (según vestigios florales persistentes en los frutos). Fruto 3- 
$4 \times 1.6-2.1 \mathrm{~cm}$, bi o trilocular, elipsoide a oblongoelipsoide, con 2-5 depresiones longitudinales, aunque cuando juveniles globosos y depresiones no marcadas, epicarpo denso y pardo híspido, tricomas de $2-4 \mathrm{~mm}$, base levemente cuneada, mesocarpo $c a .1 \mathrm{~mm}$ de grosor, endocarpo leñoso, liso.

Distribución. Endémica en Costa Rica, conocida únicamente por el ejemplar tipo, de bosques muy húmedos e inundados de la vertiente caribe en las llanuras de Tortuguero, $c a .5 \mathrm{~m}$ de elevación.

Fenología. Frutos en febrero.

Dichapetalum inopinatum se reconoce por su hábito escandente, tallos fistulosos (en el único espécimen conocido), ramitas esparcido-hirsutas, lámina foliar esencialmente glabra en el haz y esparcido-hirsuta sobre la venación en el envés, estípulas con el margen fimbriado, persistentes a deciduas en nudos inferiores, inflorescencias peciolares a terminales y frutos elipsoides a obovado-elipsoides, con densa pubescencia pardo híspida.

Esta especie es similar a $D$. hammelii por hábito escandente, estípulas fimbriadas y forma e indumento de los frutos; sin embargo, esta última tiene estípulas más grandes y divididas, hojas y estambres igualmente más grandes, indumento más denso, inflorescencias axilares o terminales y se encuentra restringida al sur de la vertiente pacífica (ver clave y comentarios respectivos).

También, $D$. inopinatum es similar a $D$. grayumii y ambas podrían ser simpátricas; sin embargo, esta última tiene el envés de la lámina densamente hirsuto, frutos globosos e inflorescencias axilares. D. bullatum (Guatemala, Honduras y dudosamente Nicaragua) está igualmente relacionada; sin embargo, se distingue por las hojas más grandes, abolladas, coriáceas y densamente hirsutas en el envés.

Un espécimen estéril (R. Aguilar s.n., LSCR) de sitios anegados en La Virgen de Sarapiquí, Heredia, posiblemente corresponde a esta especie.

Etimología. El epíteto latino inopinatum significa inesperado, ya que el tipo es el único espécimen fértil conocido y se recolectó hace cerca de 20 años. La nueva especie también es inesperada porque cuando comenzamos la revisión del género no pensamos que podía aparecer otra especie, aparte de $D$. reliquum, en un género tan pequeño.

Dichapetalum moralesii Prance, Kew Bull. 52(1): 216. 1997. Tipo. Costa Rica. Heredia: Sarapiquí, Z.P. La Selva, camino a Q. Cantarrana, Hartshorn 2558
(Holotipo: $\mathrm{K}$, isotipos: $\mathrm{CR}, \mathrm{MO}, \mathrm{NY}$ ).

Árbol, ca. 5-6(-25) m; tallitos medulosos, tomentosos o hirsútulos. Estípulas 3-15 mm, lineares a lineardeltoides, margen entero, persistentes. Pecíolo 2-12 $\mathrm{mm}$, con indumento similar al de los tallitos; láminas foliares 9-26 x 3.5-13 cm, elípticas a obovado-elípticas, membranáceas a cartáceas, base cuneada, obtusa o subcordada, ápice corto-acuminado, 8-15 pares de venas secundarias, haz liso, esparcido-pubescente a glabrado con la edad, envés densamente tomentuloso. Inflorescencias 4-6 x 3-7 cm, axilares, peciolares o terminales, ejes tomentulosos a hirsútulos; pedúnculos 2-25 mm, en ocasiones apenas distinguibles; brácteas y bracteolas 2-10 mm, lanceoladas a linear-lanceoladas; pedicelos $0.5-2 \mathrm{~mm}$. Flores hermafroditas; sépalos 2-3 mm; pétalos 2.5-3 mm, divididos ca. 1/4-1/2 de su longitud; filamentos $2.5-3.5 \mathrm{~mm}$; anteras $0.4 \mathrm{x}$ $0.25 \mathrm{~mm}$. Glándulas del disco de 0.5-0.9 x 0.25-0.35 $\mathrm{mm}$, obovadas, enteras. Ovario bi o trilocular sobre un estipite $c a$. $0.75 \mathrm{~mm}$; estilos 2-3, 0.25-0-35 mm, unidos ca. $1 / 2$ de su longitud. Fruto $1.5-2$ x 1-1.5 cm, uni a trilocular, elipsoide a obovado, epicarpo pardo tomentuloso, tricomas reducidos, base cuneada, con una sola semilla al madurar, mesocarpo 4-6 $\mathrm{mm}$ de grosor, en docarpo leñoso, acostillado.

Distribución. Endémica en la vertiente caribe de Costa Rica, en bosques muy húmedos de las llanuras de San Carlos, llanuras de Tortuguero y de las faldas de la Cordillera Central, 15-530 m de elevación.

Fenología. Flores en abril; frutos en octubre.

Dichapetalum moralesii se caracteriza por hábito arbóreo, ramitas jóvenes, envés de las hojas y ejes de inflorescencias denso-pubescentes, estípulas en la mayoría de los casos persistentes, con el margen entero, con frecuencia conspicuas, pecíolos reducidos (en ocasiones con 2-3 dientes diminutos, difíciles de notar) e inflorescencias axilares, terminales o peciolares.

Dichapetalum moralesii es muy afín a $D$. donnellsmithii y apenas se diferencia de éste por las estípulas más cortas y deciduas y por los estambres y las glándulas del disco con frecuencia más pequeños; además, se encuentra restringida a mayor elevación. Tales diferencias no son totalmente satisfactorias para separar ambas especies; no obstante, hemos decidido mantenerlas hasta que se recolecte más material de $D$. moralesii, una especie poco conocida.

Otra especie estrechamente relacionada es $D$. axillare, que presenta similitud en hábito, inflorescencias, flores 


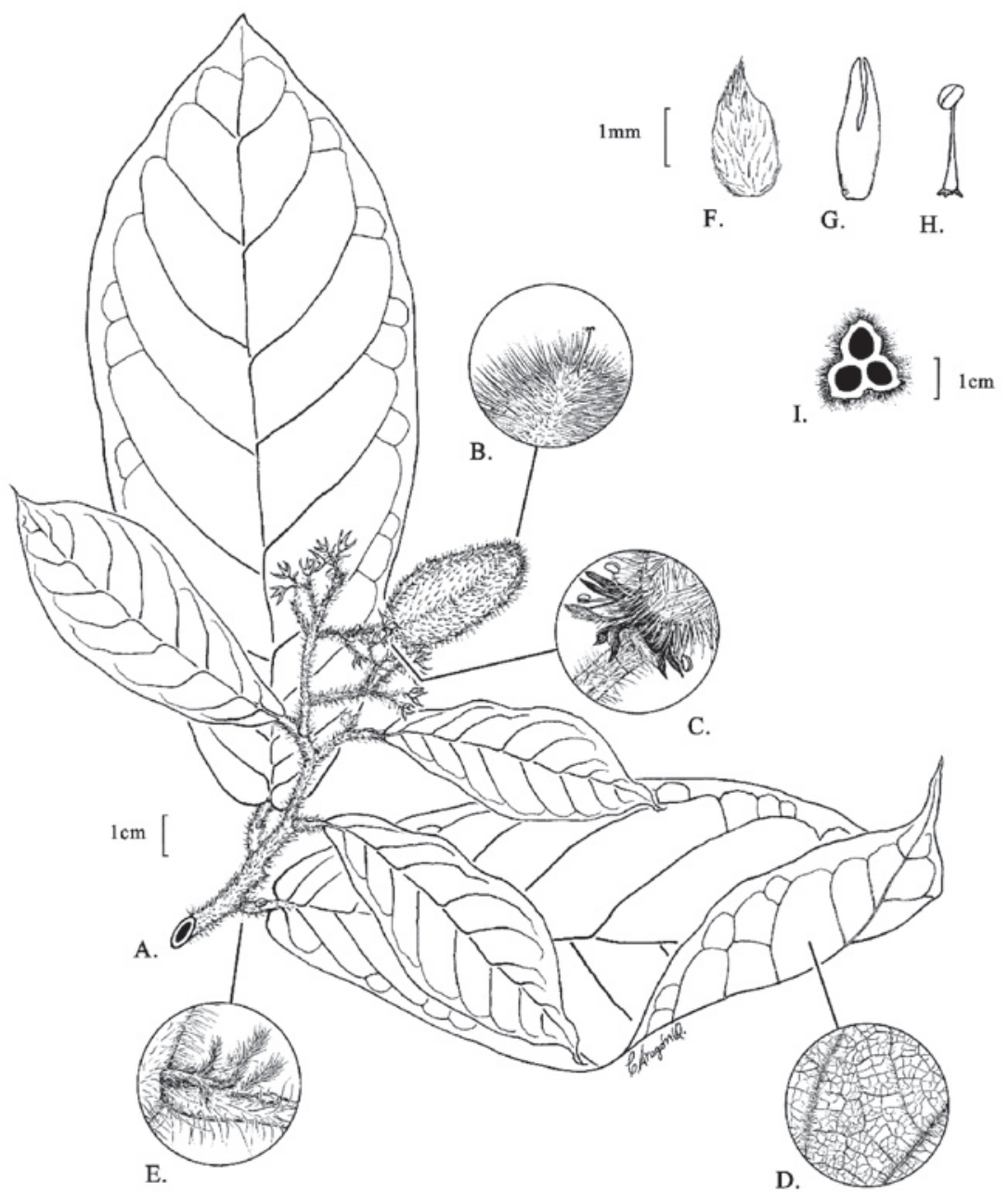

Fig. 1. Dichapetalum inopinatum Al. Rodr. \& Kriebel (Soto s.n., CR-11699). - A. Hábito. - B. Estilo y estigma persistentes en los frutos. - C. Vestigios florales presentes en los frutos. - D. Nervadura en el envés de las hojas. - E. Estípula. - F. Bráctea de inflorescencia. - G. Pétalo - H. Estambre. - I. Corte transversal de fruto.

y frutos; sin embargo, esta última tiene hojas con los tricomas en el envés restringidos a la venación (vrs. venación y superficie), flores con estambres y glándulas más cortos, estilos más largos y frutos con endocarpo liso. En la publicación de D. moralesii (Prance 1996), el único paratipo citado por el autor (J.F. Morales 268, $C R$ ) corresponde a un ejemplar de $D$. donnell-smithii, con las diferencias indicadas arriba. Lamentablemente, la ilustración presentada por el autor se basó en este paratipo.

Especímenes examinados. Costa Rica. Cartago:
Turrialba, Pavones, 650 m, 18 jun 1972, L. J. Poveda 105 (CR); Turrialba, Pavones, 11 jun 1972, L.R. Holdridge 6734 (CR). Limón: P.N. Tortuguero, Llanuras de Tortuguero, Sardinas, $10^{\circ} 38^{\prime} \mathrm{N}, 83^{\circ} 44^{\prime} \mathrm{W}$, 15-20 m, 20 abr 1993, F. Araya et al. 232 (CR, INB, MO). Heredia: La Selva Protection Zone, along road to Quebrada Cantarrana, 350 m, 20 Jan 1983, G. Hartshorn 2558 (CR, K, MO, NY).

Dichapetalum morenoi Prance, Kew Bull. 52(1): 216, 218-219. 1997. Tipo: Nicaragua, Río San Juan, La Gloria, Moreno 25468 (Holotipo: K, isotipo: MO). 
Arbusto o árbol pequeño, 3-6 (-10) $\mathrm{m}$; tallitos medulosos, esparcidamente puberulentos a glabrados con la edad. Estípulas 2-7 mm, lineares a linearlanceoladas, margen entero, deciduas a persistentes en ramitas terminales. Pecíolos $2.5-7 \mathrm{~mm}$, puberulentos; láminas foliares 3.5-14 (-24) x 1.2-3.5 (-6) cm, angostolanceoladas, lanceoladas, angosto-elípticas a oblongolanceoladas, cartáceas, base cuneada, ápice largoacuminado, 7-13 pares de venas secundarias, haz liso, glabro, con algunos tricomas adpresos e inconspicuos sobre el nervio central y sobre algunos nervios secundarios en el envés. Inflorescencias 1.5-4 x 1.8$4.5 \mathrm{~cm}$, axilares, terminales o menos frecuentemente peciolares, ejes tomentosos; pedúnculos 4-17 mm, en ocasiones apenas distinguibles; brácteas y bracteolas 0.5-1.75 mm, lanceoladas a linear-lanceoladas; pedicelos 1-2.75 $\mathrm{mm}$. Flores hermafroditas; sépalos 1-1.5 mm; pétalos 1.25-1.5 mm, divididos cerca de la mitad de su longitud; filamentos 1.3-1.6 mm; anteras ca. 0.35 x $0.3 \mathrm{~mm}$. Glándulas del disco de 0.4-0.6 x 0.25-0.3 mm, obovadas, diminuto lobadas. Ovario bi o trilocular, estípite $0.1-0.25 \mathrm{~mm}$; estilos 2-3, 0.75-1.1 mm, unidos $c a \cdot 1 / 2-2 / 3$ de su tamaño, con frecuencia divididos hasta la base. Fruto inmaduro $c a .0 .8$ x $1.3 \mathrm{~cm}$, bi o trilocular, globoso a globoso-elipsoide, epicarpo velutino-tomentoso, base obtusa, estípite $c a$. $0.5 \mathrm{~mm}$, mesocarpo 1-2 mm de grosor, endocarpo más o menos leñoso, estriado, el único fruto examinado con dos semillas.

Distribución. Nicaragua y Costa Rica. En Costa Rica se conoce en bosques secos, húmedos y muy húmedos a lo largo de toda la vertiente pacífica, desde las llanuras de Guanacaste hasta la Península de Osa; además, en la misma vertiente de la Cordillera de Guanacaste; también se ha recolectado al norte de la vertiente caribe, en llanuras de San Carlos, 1-1100 m de elevación.

Fenología. Flores de junio a setiembre; frutos en marzo y setiembre.

Dichapetalum morenoi se reconoce por sus hojas estrechas (hasta 7 veces más largas que anchas) y esencialmente glabras; además, se caracteriza por ser un arbusto o árbol pequeño con ramitas esparcidamente puberulentas, con estípulas de margen entero, deciduas (al menos en nudos inferiores), hojas con el ápice largo acuminado, inflorescencias generalmente axilares, ovario bi o trilocular, estilos 2 ó 3 y por los frutos globosos, con densa pubescencia velutino-tomentosa.

Material de bosques húmedos, desde el Parque
Nacional Carara hasta la Península de Osa (Aguilar 4713, 4869, Gentry 79479, Zamora 2097), representa a árboles de mayor altura con hojas más grandes. Nuevos especímenes harán posible un mejor diagnóstico del material discutido.

Dichapetalum morenoi es similar a $D$. axillare, de la cual se diferencia porque esta última posee hojas más anchas, usualmente oblongo-obovadas, en la mayoría de los casos con pubescencia evidente en los tallitos y venación en el envés de la hoja, estípulas evidentes y persistentes, frutos ovoides y debido a que se restringe a bosques húmedos (nunca en bosques secos). D. morenoi también es similar a $D$. brenesii, una especie que crece a mayor elevación. Uno de los caracteres diagnósticos de D. morenoi (Prance 1996) son las inflorescencias insertas siempre en los pecíolos. Después de revisar el material disponible con flores (U. Chavarría 1550, 1593, L. Acosta 1134, A. Estrada 216), así como el único paratipo citado ( $R$. Espinoza 210), hemos concluido que las inflorescencias en esta especie son generalmente axilares, en ocasiones también terminales y excepcionalmente están insertas en los pecíolos.

Especímenes examinados. Costa Rica. Guanacaste: La Cruz, P.N. Guanacaste, Estación Maritza, $10^{\circ} 55^{\prime} \mathrm{N}, 85^{\circ} 29^{\prime} \mathrm{W}, 1100 \mathrm{~m}, 1$ mar 1992, $R$. Espinoza 210 (CR, INB, K, MO); La Cruz, P.N Guanacaste, cuenca del Sapoá, Sector Maritza, $10^{\circ} 57^{\prime} \mathrm{N}, 8^{\circ} 29^{\prime} \mathrm{W}, 600 \mathrm{~m}, 2$ jun 2000 , L. Acosta et al. (CR, INB, MO); Santa Cruz, R.V.S. Bosque Diriá, cuenca del Tempisque, camino a la torre, vista del mar, $10^{\circ} 08^{\prime} \mathrm{N}, 85^{\circ} 37^{\prime} \mathrm{W}, 300-960 \mathrm{~m}, 23$ sept 1996, U. Chavarría et al. 1550 (CR, INB, MO); Santa Cruz, Cuenca del Tempisque, siguiendo Río Enmedio, de la administración hasta Quebrada Chauita, $10^{\circ} 10^{\prime} \mathrm{N}, 85^{\circ} 35^{\prime} \mathrm{W}, 210 \mathrm{~m}, 24$ sept $1996, U$. Chavarría et al. 1593 (CR, INB, MO); Nandayure, Península de Nicoya, Bejuco, Islita, Finca de Abel Rodríguez, 9'52'N, 85'23'W, 100-420 m, 13 sept 1994, A. Estrada \& A. Rodríguez 216 (CR, INB, MO). Puntarenas: Península de Nicoya, R.N.A. Cabo Blanco, Estación San Miguel, ca. $2 \mathrm{~km} \mathrm{~S} \mathrm{de}$ Malpaís, $09^{\circ} 35^{\prime} \mathrm{N}, 85^{\circ} 07^{\prime} \mathrm{W}, 0-200 \mathrm{~m}, 18$ ene 1996 , B. Hammel et al. 20110 (CR, INB, MO); Osa, R.F. Golfo Dulce, Cuenca Térraba-Sierpe, Bahía Chal, $8^{\circ} 43^{\prime} \mathrm{N}, 83^{\circ} 27^{\prime} \mathrm{W}, 150$ m, 25 sept 1996, R. Aguilar 4713 (CR, INB, MO).

Dichapetalum nervatum Cuatr., Lloydia 11: 222. 1949.Tipo: Colombia, Valle, Río Yurumangui, 
Cuatrecasas 15833 (Holotipo: F, isotipo: COL).

Lianas; tallitos medulosos, ramitas terminales esparcido-pilosas a densamente tomentulosas, ramitas inferiores glabradas. Estípulas 5-10 mm, lanceoladas, con el margen fimbriado (en apariencia pinnatífidas), deciduas en la mayoría de los casos, a veces persistentes al menos en ramitas terminales. Pecíolos 6-15 mm, esparcido a denso-pubescentes; láminas foliares 5-20 x 3-8.5 cm, oblongo-elípticas a oblongo-obovadas, subcoriáceas, base obtusa a subcordada, en ocasiones levemente asimétrica, ápice acuminado, 7-13 pares de venas secundarias, haz débilmente abollado, glabrado a esparcido-estriguloso, envés glabrado en la superficie y con inconspicuos tricomas adpresos restringidos a los nervios principales. Inflorescencias 8-12 x 7-9 $\mathrm{cm}$, axilares, terminales o menos frecuente peciolares, ejes tomentulosos; pedúnculos 4-15 mm, en ocasiones apenas distinguibles; brácteas y bracteolas 2-6 mm, lanceoladas; pedicelos 2-3 mm. Flores hermafroditas; sépalos 1.75-2.5 $\mathrm{mm}$; pétalos $2.5-3 \mathrm{~mm}$, divididos hasta cerca de la mitad de su longitud; filamentos 3-3.5 $\mathrm{mm}$; anteras $0.5 \times 0.3 \mathrm{~mm}$. Glándulas del disco 0.25 $0.4 \times 0.3-0.5 \mathrm{~mm}$, obovadas, diminutamente lobadas. Ovario bi o trilocular, estípite $c a .0 .5 \mathrm{~mm}$, estilos 23, 0.75-1.5 mm, unidos $c a .5 / 6$ de su longitud. Fruto ca. $11.5-2.3 \times 1.3-2.7 \mathrm{~cm}$, bi o trilocular, elipsoides a obovados, con 2-3 depresiones longitudinales, pardo tomentulosos, base obtusa a subtruncada, en ocasiones abortando uno o dos lóculos, con una sola semilla al madurar, mesocarpo 2-3 $\mathrm{mm}$ de grosor, endocarpo leñoso, liso.

Distribución. Costa Rica, Colombia y Ecuador. En Costa Rica se conoce de la vertiente caribe, en bosques muy húmedos de las llanuras de Tortuguero (E.B. La Selva) y de la Cordillera de Guanacaste, 50-740 m de elevación.

Fenología. Flores en octubre; frutos en marzo.

Dichapetalum nervatum se caracteriza por hábito trepador, estípulas con el margen fimbriado, pecíolos más o menos alargados, láminas foliares con el envés glabrado en la superficie y con tricomas adpresos restringidos a los nervios principales, inflorescencias peciolares, axilares o terminales, flores con estambres alargados, estilos unidos en gran parte de su tamaño y frutos tomentulosos, con 2-3 depresiones que le dan una apariencia angulada.

En Costa Rica la única especie similar por hábito escandente, forma de hojas, estípulas fimbriadas, con la que podría ser simpátrica, es Dichapetalum grayumii; sin embargo, D. nervatum se distingue debido a sus pecíolos más cortos, envés de las hojas denso-hirsuto, estambres más cortos y frutos globosos e híspidos.

Entre las especies costarricenses con estípulas fimbriadas, solamente $D$. nervatum posee el endocarpo del fruto tomentuloso; las otras tres: D. grayumii, $D$. hammelii y $D$. inopinatum, tienen endocarpo híspido con tricomas rígidos y urticantes cuando se adhieren a la piel.

También, entre las especies con estípulas fimbriadas, $D$. nervatum es similar a D. stipulatum J.F. Macbr. (Amazonia peruana), que se distingue de la primera según Prance $(1977,1979,1996)$ por pedicelos de 5 $\mathrm{mm}$ e inflorescencias densamente café-tomentosas; diferencias que él mismo establece como tentativas debido a que un mayor número de especímenes podría probar que ambas son coespecíficas.

Prance (1972), basado en el ejemplar tipo, describe esta especie con hábito arborescente, pecíolos hasta $5 \mathrm{~mm}$, lámina foliar hasta $13 \times 5.5 \mathrm{~cm}$ y frutos uniloculares. En Costa Rica, los especímenes que se pueden atribuir a esta especie se indican en herbario como lianas y nuestro trabajo de campo comprueba esta interpretación. Aún así, las plantas jóvenes empiezan su desarrollo con apariencia arbustiva. Además, los pecíolos y la lámina foliar se notan más grandes y los frutos se han observado con 2 o 3 lóculos. En el resto de caracteres, el material costarricense concuerda satisfactoriamente con $D$. nervatum.

Especímenes examinados. Costa Rica. Alajuela: Upala, Dos Ríos, $10 \mathrm{~km}$ al noreste del pueblo, asentamiento campesino San Gil, $10^{\circ} 56^{\prime} \mathrm{N}$, $85^{\circ} 18^{\prime} \mathrm{W}, 400$ m, 7 abr 1988, G. Herrera 1723 (CR). Guanacaste: P.N. Guanacaste, estación Pitilla, Fila Orosilito y sendero El Mismo, $10^{\circ} 59^{\prime} \mathrm{N}, 85^{\circ} 25^{\prime} \mathrm{W}$, 700 m, 2 mar 1991, P. Ríos 325 (CR, INB, MO). Heredia: Sarapiquí, Puerto Viejo, Finca La Selva, $10^{\circ} 26^{\prime} \mathrm{N}, 84^{\circ} 01^{\prime} \mathrm{W}, 19$ ene 1974, G. Hartshorn 1346 (CR); Sarapiquí, E.B. La Selva, at confluence of Río Sarapiquí and Río Puerto Viejo, $10^{\circ} 26^{\prime} \mathrm{N}, 84^{\circ} 01^{\prime} \mathrm{W}$, 50 m, 23 Oct 1991, B. Hammel et al. 18375 (CR, INB, MO); Sarapiquí, cuenca del Sarapiquí, Horquetas, camino a Rara Avis, $10^{\circ} 20^{\prime} \mathrm{N}, 84^{\circ} 00^{\prime} \mathrm{W}, 250 \mathrm{~m}, A$. Rodríguez et al. 3319 (CR, INB, MO).

Dichapetalum nevermannianum Standl. \& Valerio, Publ. Field Mus., Bot. Ser. 18: 597. 1937. Tipo: Costa Rica, Limón, Río Reventazón, bajo Cairo; Standley \& Valerio 48497 (Holotipo: F, isotipos: EAP, G, US). 
Arbusto o arbolito pequeño, 1-3 m; tallitos medulosos, con pubescencia heterótrica, entremezclando tricomas híspidos de 1-3 mm y una capa superficial de tricomas reducidos e incurvos. Estípulas 4-8 mm, lineares, margen entero, persistentes, en ocasiones deciduas en nudos inferiores. Pecíolos 2-5 mm, denso-hirsutos, lámina foliar 5-15 x 1.5-4 cm, oblongo-lanceolada a oblongo-obovada, membranácea, base levemente oblicua, obtusa a subcordada, ápice acuminado, 813 pares de venas secundarias, haz no abollado, igual que el envés esparcido-híspido, principalmente hacia los nervios principales, tricomas de 1-2 $\mathrm{mm}$. Inflorescencias $2-3 \times 1.5 \mathrm{~cm}$, terminales, ejes híspidos; pedúnculos $2-5 \mathrm{~mm}$, en ocasiones apenas distinguibles; brácteas y bracteolas 3-6 mm, linearsubuladas; pedicelos 1.5-3 mm. Flores hermafroditas. Sépalos 2-3 mm; pétalos 2-2.5 mm, divididos $c a$. 1/4 de su longitud. Filamentos 1.75-2 mm; anteras 0.30.5 x 0.2-0.25 mm. Glándulas del disco 5, libres, cada una de $c a .0 .5 \times 0.25 \mathrm{~mm}$, obovadas. Ovario bilocular, sobre un estípite $c a .0 .2 \mathrm{~mm}$, esparcido-pubescente, estilos 2, 1.5-1.75 mm, unidos ca. 4/5 de su longitud. Fruto inmaduro $1 \times 1 \mathrm{~cm}$, uni a trilocular, elipsoide a obovado-elipsoide, epicarpo con densa pubescencia hirsuta, base obtusa.

Distribución. Costa Rica y Panamá. En Costa Rica se conoce en los bosques muy húmedos de la vertiente caribe, en Baja Talamanca y llanuras de Tortuguero, 70-220 m de elevación.

Fenología. Flores y frutos en setiembre.

Dichapetalum nevermannianum Standl. \& Valerio se reconoce por hábito de arbusto o arbolito pequeño, pubescencia de tallitos entremezclando tricomas alargados y tricomas reducidos e incurvos, láminas estrechas (hasta 4.5 veces más largas que anchas), esparcidamente híspidas, estípulas lineares, enteras y generalmente persistentes, inflorescencias terminales, paucifloras y cortas, flores con 2 estilos largamente connados y por frutos elipsoides a obovado-elipsoides, con densa pubescencia hirsuta.

Esta especie se relaciona con D. reliquum (ver clave y discusión respectiva). También es similar a $D$. coelhoi Prance y $D$. pauper Rizzini, ambas especies de Brasil, con hojas estrechas y pubescencia híspida en el envés, pero con hábito escandente y hojas coriáceas con haz glabro.

Especímenes examinados. Costa Rica. Limón: Faja Costeña de Limón, San Rafael de Pandora, $09^{\circ} 48^{\prime} \mathrm{N}$, $82^{\circ} 59^{\prime} \mathrm{W}, 220$ m, 10 sept 1995, A. Rodríguez 852
(CR, INB, MO); P.N. Tortuguero, Estación Agua Fría, segunda loma aprox. $7 \mathrm{~km}$ al sureste, Cerros Azules, $10^{\circ} 27^{\prime} \mathrm{N}, 83^{\circ} 34^{\prime} \mathrm{W}, 70 \mathrm{~m}, 21$ ene 1988 , R. Robles 1561 (CR); P.N. Tortuguero, Lomas de Sierpe, $4 \mathrm{~km}$ al NE del puesto sobre el Río Sierpe, $10^{\circ} 24^{\prime}$ N, $83^{\circ} 33^{\prime} \mathrm{W}, 100$ m, 15 ago 1988, R. Robles et al. 2051 (CR).

Dichapetalum odoratum Baill., Fl. Bras. 12(1): 371. 1886. Tipo: Brasil, Amazonas, Panuré; Spruce 2864 (Holotipo: P, isotipos: BM, BR, C, CGE, F, G, GH, GOET, K, LE, NY, OXF, P, RB, W).

Liana; tallitos medulosos, en ocasiones fistulosos en partes inferiores, conspicuamente lenticelados, ramitas terminales farinoso-puberulentas, rápidamente glabradas, tricomas hasta $0.25 \mathrm{~mm}$. Estípulas 0.4$6 \mathrm{~mm}$, lineares a linear-deltoides, margen entero, deciduas. Pecíolos 0.3-1.5 cm, glabrados a esparcidopuberulentos; lámina foliar 2.5-16 x 2-7 cm, elíptica a oblongo-elíptica, coriácea, base obtusa a subcordada, ápice corto-acuminado, 6-10 pares de venas secundarias, haz liso, glabro a esparcido-puberulento, envés farinoso-puberulento en hojas nuevas, pronto glabrescentes aunque algunas hojas manteniendo parches indumentados, tricomas hasta $0.25 \mathrm{~mm}$. Inflorescencias 3-7 x 1.5-9 cm, peciolares, terminales o menos frecuentemente axilares, ejes puberulentos y lenticelados; pedúnculos $5-15 \mathrm{~mm}$; brácteas y bracteolas $0.75-2 \mathrm{~mm}$, lanceoladas; pedicelos 2-4 $\mathrm{mm}$. Flores con sépalos 2-2.5 mm; pétalos $1.75-2 \mathrm{~mm}$, divididos $c a$. 1/5 de su longitud, glabros. Filamentos 1.5-1.75 mm; anteras $c a .0 .5 \times 0.4 \mathrm{~mm}$. Ovario bi o trilocular, estilos 2-3, unidos $c a$. 4/5 de su longitud (según vestigios florales persistentes en frutos). Fruto inmaduro $\mathrm{ca} .2 \times 1.2 \mathrm{~cm}$, bi o trilocular, obovado a obovado-elipsoide, con 3 depresiones longitudinales que le dan apariencia triquetra, epicarpo pardotomentuloso, base atenuada, mesocarpo $1-1.5 \mathrm{~mm}$ de grosor, endocarpo leñoso, liso.

Distribución. Costa Rica y el oeste de la Amazonia en Venezuela, Perú y Brasil. En Costa Rica se encuentra en la vertiente caribe, en bosques pluviales de las cordilleras Central y de Talamanca, 1350-1500 $\mathrm{m}$ de elevación.

FEnología. Flores no observadas; frutos en abril.

Dichapetalum odoratum se diferencia de las otras especies costarricenses por tallitos e incluso ejes de la inflorescencia densamente lenticelados, envés de las hojas farinoso-puberulentos en ramitas terminales, aunqueprontoglabrescentes, y porpecíolos enocasiones 
con 1-2 dientes diminutos (este último carácter también presente en $D$. brenesii y $D$. pedunculatum); además, se distingue por hábito escandente, hojas coriáceas, tallos con frecuencia fistulosos, estípulas deciduas, lineares, inflorescencias generalmente peciolares y por frutos pardo-tomentulosos.

Hemos determinado dos especímenes costarricenses con este nombre, pero con ciertas reservas, porque el material tipo de D. odoratum, de la Amazonia brasileña, difiere del material costarricense en que posee hojas más anchas (hasta $9 \mathrm{~cm}$ ), elípticas a obovado-elípticas, envés glabrado a esparcido-pubescente, pecíolos más cortos (hasta $0.8 \mathrm{~mm}$ ), pétalos profundamente partidos y ovario bilocular.

Uno de los dos especímenes costarricenses (Burger \& Liesner 6765, CR) fue anotado como D. donnellsmithii por Prance, especie que posee dos variedades. Dicho ejemplar se ajustaría más convenientemente a D. donnell-smithii var. chiapense, por la forma de las hojas y el tamaño de las estípulas. Sin embargo, D. donnell-smithii var. chiapense se distingue del material aquí descrito debido a que posee un hábito generalmente arbustivo o arbóreo, pecíolos, estípulas y láminas foliares llegan a ser más cortos (en el orden respectivo hasta $0.8 \mathrm{~cm}, 3 \mathrm{~mm}, 13 \mathrm{~cm})$, los ejes de las inflorescencias son fulvo-tomentosos y los frutos uni o biloculares.

Dichapetalum odoratum se encuentra estrechamente relacionado con D. pedunculatum por hábito escandente, forma de estípulas y hojas, pecíolos a menudo diminuto-dentados adaxialmente, inflorescencias con frecuencia peciolares y tipo de pubescencia de los frutos. Sin embargo, esta última especie presenta lenticelas esparcidas o nulas en tallitos, pubescencia farinoso-puberulenta en las ramitas, no así en el envés de las hojas, frutos arqueado-fusiformes con un ápice prolongado y se halla generalmente a menor elevación. Para ver diferencias con con $D$. brenesii, una especie similar de hábito arbustivo o arborescente, ver clave y discusión bajo esa especie.

D. odoratum también es similar a $D$. steyermarkii Prance (Venezuela), una liana distintiva por su condición polígamo-dioica, estípulas más cortas (hasta $2 \mathrm{~mm}$ ) y ovario bilocular.

Especímenes examinados. Costa Rica. Cartago: 15 $\mathrm{km}$ south of Tapantí along new road, on the east slope above the Río Grande de Orosi, 942'N, 83ำ $47^{\prime} \mathrm{W}, 1500$ m, 12,14,17 Dec 1969, Burger \& Liesner 6765 (CR). Limón: El Progreso, Cabecera de Río Aguas Zarcas, Fila Matama, Valle de la Estrella, $9^{\circ} 47^{\prime} \mathrm{N}, 83^{\circ} 08^{\prime} \mathrm{W}$,
1350 m, 29 abr 1989, G. Herrera \& A. Chacón 2854 (CR, INB, MO).

Dichapetalum pedunculatum (DC.) Baill., Hist. P1. 5: 140. 1874. Chailletia pedunculata DC., Nouv. Bull. Sci. Soc. Philom. Paris 40: 205. 1811. Tipo: Guyana Francesa, Patris s.n. (Holotipo: G-DC).

Liana; tallitos medulosos, farinosos y con algunos tricomas simples entremezclados. Estípulas 0.3-6 mm, lineares, margen entero, deciduas. Pecíolo 4-11 mm, farinoso, con algunos tricomas simples; lámina foliar 5-16 x 2-5.5 cm, elíptica, oblongo-elíptica a obovadoelíptica, cartácea, base obtusa a cuneada, ápice acuminado, 7-10 pares de venas secundarias, haz y envés glabros a estrigulosos sobre la vena media, con tricomas 0.1-1 mm. Inflorescencias 2.2-4.6 x 2.5-5.6 cm, peciolares y terminales, o menos frecuentemente axilares, ejes farinoso, entremezclando algunos tricomas simples; pedúnculos 4-17 mm, en ocasiones apenas distinguibles; brácteas y bracteolas 0.5-1.75 mm, lanceoladas a linear-lanceoladas; pedicelos 1-2.75 mm. Flores hermafroditas. Sépalos 2-2.5 mm; pétalos 2$2.5 \mathrm{~mm}$, divididos $1 / 2-3 / 4$ de su longitud. Filamentos 1.25-1.8 mm; anteras ca. $0.45 \times 0.35 \mathrm{~mm}$. Glándulas del disco 5, libres, cada una ca. 1 x 0.75-0.3 mm, elipsoide, conspicuamente bilobada. Ovario bi o trilocular, estípite $0.5-0.6 \mathrm{~mm}$, estilos $2(-3), c a .0 .5 \mathrm{~mm}$, libres o unidos hacia la base. Fruto inmaduro ca. $2.3 \times 0.5$ $\mathrm{cm}$, unilocular (a veces bi o trilocular), arqueado-fusiforme (maduro aparentemente obovoide), levemente acostillado, pardo-tomentuloso, base atenuada, mesocarpo 0.2-1 mm de grosor, endocarpo no leñoso, liso.

Distribución. Costa Rica, Panamá, Colombia, Venezuela, las Guyanas y la Amazonia. En Costa Rica lo encontramos en la vertiente caribe, en bosques muy húmedos de las llanuras de Tortuguero y de Baja Talamanca, 400-1200 m de elevación.

FENOLOGÍA. Flores entre setiembre y noviembre; frutos en febrero.

Dichapetalum pedunculatum se reconoce por hábito trepador, tallitos y ejes de inflorescencias con indumento farinoso entremezclado con algunos tricomas simples, hojas glabrescentes, estípulas lineares, deciduas, inflorescencias principalmente peciolares y frutos pardo-tomentulosos.

Esta especie es fácil de confundir con D. brenesii por similitud vegetativa, pecíolos con dientes diminutos e inflorescencias peciolares; sin embargo, esta última 
posee hábito estrictamente arbustivo o arborescente, pubescencia no farinosa, frutos ovoide-elípticos sin ápice prolongado y se encuentra a mayor elevación.

Dichapetalum pedunculatum es muy similar a $D$. odoratum; sin embargo, ésta se distingue (Prance $1972,1979,1996)$ por pedicelos más largos $(1-3 \mathrm{~mm})$ estípulas más cortas $(0.5-2 \mathrm{~mm})$ e inflorescencias tomentulosas a glabras (vrs. tomentulosas a esparcidopubescentes). Como reflejan los caracteres anteriores, las diferencias entre ambas especies son muy estrechas, razón por la cual es necesario un estudio más detallado de ambos taxa. Un punto relevante es que los frutos de D. odoratum no se conocen.

Especímenes examinados. Costa Rica. Cartago: Turrialba, $6 \mathrm{~km} \mathrm{~N}$ of La Suiza on the road to Pacayitas, $9^{\circ} 42^{\prime} \mathrm{N}, 8^{\circ} 35^{\prime} \mathrm{W}, 1200$ m, 8 Sept 1990, J. Solomon 19246 (INB, MO). Heredia: Sarapiquí, Rara Avis, ca. $15 \mathrm{~km}$ al suroeste de Horquetas, camino Leví, $10^{\circ} 17^{\prime} \mathrm{N}, 84^{\circ} 02^{\prime} \mathrm{W}, 400 \mathrm{~m}, 9$ oct. 1989, O. Vargas 206 (CR, INB, MO). Limón: Guápiles, Los Ángeles, San Miguel, siguiendo el camino al Volcán Irazú, cuenca media del Río Blanquito, margen izquierdo, $10^{\circ} 06^{\prime} \mathrm{N}$, 8459'W, 1100 m, 26 febr 1990, G. Herrera \& S. Schik 3825 (CR, INB, MO); Pococí, Cordillera Central, teleférico del bosque lluvioso, $10^{\circ} 10^{\prime} \mathrm{N}, 83^{\circ} 54^{\prime} \mathrm{W}, 500$ m, 28 nov 1994, B. Hammel et al. 19706 (CR, INB, $\mathrm{MO})$.

Dichapetalum reliquum Kriebel \& Al. Rodr., sp. nova Tipo: Costa Rica. San José: Ciudad Colón, Zona Protectora El Rodeo, márgenes del Río Jaris, $9^{\circ} 53^{\prime} \mathrm{N}$, $84^{\circ} 16^{\prime} \mathrm{W}, 700$ m, 24 jul 2003, R. Kriebel \& A. Rodríguez 3419 (Holotipo: INB, isotipos: CR, INB, K, MO, NY, USJ). Fig. 2

A Dichapetalo nevermanniano Standl. \& Valerio affinis, sed planta scandenti, stipulis deciduis, foliis 3.5$5.5 \mathrm{~cm}$ latis, dense hirsutis recedit; D. coelhoi Prance et D. paupere Rizzini similis, sed foliis membranaceis, subtus dense hirsutis dignoscenda.

Lianas; tallitos medulosos, denso-hirsutos, tricomas 0.3-1.25 mm. Estípulas 6-9 mm, lineares, margen entero, deciduas. Pecíolos 4-7 mm, denso-hirsutos; lámina foliar $8-16.5$ x 3-5.5 cm, oblongo-lanceolada a oblongo-elíptica, membranácea, base subcordada, ápice acuminado, 9-11 pares de venas secundarias, haz liso, igual que el envés denso-hirsuto, principalmente en los nervios principales, tricomas $0.5-1.5 \mathrm{~mm}$. Inflorescencias $1.2-2 \times 1.3-2.3 \mathrm{~cm}$, terminales, ejes denso-hirsutos; pedúnculos $0.2-0.9 \mathrm{~cm}$, en ocasiones apenas distinguibles; brácteas y bracteolas 1.5-8 $\mathrm{mm}$, linear-subuladas; pedicelos 0.5-1.5 mm. Flores hermafroditas o masculinas con ovario rudimentario; sépalos $1.5-2 \mathrm{~mm}$; pétalos $1.25-1.75 \mathrm{~mm}$, divididos hasta $c a$. la mitad de su longitud, glabros, blancos, cada uno con una glándula basal; filamentos 1.25$1.75 \mathrm{~mm}$; anteras $0.25-0.35 \times 0.2-0.25 \mathrm{~mm}$. Glándulas del disco 5, libres, 0.25-0.35 x $0.25 \mathrm{~mm}$, oblongoobovadas, diminutmente lobadas en el ápice. Flores hermafroditas con ovario bi o trilocular, lanado, estípite no claramente diferenciado, estilos 2-3, 0.75$1.5 \mathrm{~mm}$, lanados en la base, glabrados distalmente; unidos ca. 4/5 de su longitud, raras veces libres hasta la base. Flores masculinas menos frecuentes, con ovario reducido, estéril, lanado, estilo igualmente reducido, ca. $0.3 \mathrm{~mm}$; estilos unidos $c a .4 / 5$ de su longitud. Fruto inmaduro $c a .1 .2 \times 0.6 \mathrm{~cm}$, elipsoide a obovadoelipsoide, epicarpo denso-hirsuto, base obtusa a levemente cuneada, bi o trilocular.

Distribución. Endémica en Costa Rica, donde se encuentra en bosques húmedos y pluviales de la vertiente pacífica, en la Zona Protectora El Rodeo, Ciudad Colón (San José) y en la Cordillera de Talamanca (San Vito de Coto Brus), 600-1290 m de elevación.

Fenología. Flores en julio; frutos en setiembre.

Dichapetalum reliquum se reconoce por hábito escandente, tallitos y hojas denso-hirsutas, estípulas lineares, enteras y deciduas, inflorescencias terminales, paucifloras, nunca peciolares, flores hermafroditas con 2-3 estilos alargados, masculinas con 2 estilos reducidos y frutos elipsoides a obovado-elipsoides, con densa pubescencia pardo hirsuta.

Esta especie está relacionada con $D$. nevermannianum (Costa Rica y Panamá) debido a similitud en indumento, forma de la lámina, tipo de inflorescencia y forma de los frutos; sin embargo, se distinguen debido a que esta última tiene hábito arbustivo o arborescente, pubescencia de los tallos heterótrica, con tricomas largos, erectos, y tricomas reducidos e incurvos (vrs. tricomas homótricos). También, los tricomas tienden a ser más largos y esparcidamente distribuidos, las estípulas son persistentes, las hojas son más estrechas y cortas, la base con frecuencia es levemente desigual, es una especie hermafrodita, las flores presentan dos estilos y se restringe a la vertiente atlántica (ver clave y comentarios sobre D. nevermanianum).

Asimismo, Dichapetalum reliquum es similar a $D$. coelhoi Prance y a D. pauper Rizzini (ambas de la 
Amazonia brasileña), que son especies escandentes con pubescencia hirsuta a hirsútula en tallitos y ejes de inflorescencias, que se distinguen porque tienen flores hermafroditas, lámina foliar coriácea con el haz glabro (vrs. membranácea con haz hirsuto); además, D. coelhoi presenta flores con 2 estilos (vrs. 2 o 3), mientras la $D$. pauper muestra estípulas más cortas (hasta $2 \mathrm{~mm}$ ), los tallitos pronto llegan a ser glabrados (vrs. siempre pubescentes), los pedicelos llegan a ser más largos (1.5-3 mm) y las bracteolas son más pequeñas (hasta $3 \mathrm{~mm}$ ).

Etimología. El epíteto latino reliquum, lo que queda, lo restante, hace alusión a que los sitios de donde se conoce la especie son los últimos relictos de los bosques de estas zonas (Ciudad Colón y San Vito).

Paratipos: Costa Rica. Puntarenas: Coto Brus, Robert and Catherine Wilson Botanic Gardens, Las Cruces Biological Station, San Vito, $8^{\circ} 47^{\prime}$ N, 82 $57^{\circ}$ 'W, 1290 m, 27 Jul 1994, W.J. Kress 4552 (CR). San José: Mora, Ciudad Colón, Z.P. El Rodeo, márgenes del Río Jaris, $9^{\circ} 53^{\prime} \mathrm{N}, 84^{\circ} 16^{\prime} \mathrm{W}, 700 \mathrm{~m}, 6$ sept 2003, R. Kriebel \& $J$. Larraguivel 3773 (INB); Mora, Cuenca del Tárcoles, El Rodeo, Bajo Morales, a orilla de Quebrada Honda, $9^{\circ} 55^{\prime} \mathrm{N}, 84^{\circ} 15^{\prime} \mathrm{W}, 800 \mathrm{~m}, 27$ mar 1998, A. Rodríguez \& L.D. Vargas 3183 (CR, INB, MO).

Dichapetalum rugosum (Vahl) Prance, Acta Bot. Venez. 3(1-4): 303-304. 1968. Symphyllanthus rugosus Vahl, Skr. Naturhist.-Selsk. 6: 88-89. 1810. Tipo: Guyana Francesa, Vahl s.n. (Holotipo: C)

Liana o arbusto subescandente; tallitos medulosos a levemente fistulosos, ramitas terminales tomentulosas, ramitas inferiores glabradas. Estípulas ca. $5 \mathrm{~mm}$, lanceoladas, con el margen entero, deciduas. Pecíolos 3-13 mm, pubescencia similar a la de los tallitos; láminas foliares 10-24 x 6-12 cm, elípticas a obovado-elípticas, cartáceas a coriáceas, base aguda a subcordada, ápice corto-acuminado o cuspidado, 7 14 pares de venas secundarias, haz rugoso a abollado, glabrado a esparcido-pubescente sobre los nervios principales, envés denso-pubescente. Inflorescencias 3$7 \times 3-7 \mathrm{~cm}$, peciolares, ejes glabrados a esparcidamente tomentulosos; pedúnculos $3-35 \mathrm{~mm}$; brácteas y bracteolas 1-2 mm, lanceoladas; pedicelos $c a .5 \mathrm{~mm}$ en frutos. Flores hermafroditas. Sépalos $c a .2 .5 \mathrm{~mm}$; pétalos no observados. Filamentos $c a .2 \mathrm{~mm}$ de largo; anteras ca. $0.5 \times 0.4 \mathrm{~mm}$. Ovario no observado, estilos no observados (en vestigios florales persistentes en frutos). Fruto 2-4 x 1-2.5 cm, oblongo-obovado a oblongo-elipsoide, con 2-3 depresiones longitudinales, epicarpo pardo tomentuloso, tricomas reducidos, base cuneada, bi o trilocular, en ocasiones abortando uno o dos lóculos, mesocarpo 1-3 mm de grosor, endocarpo leñoso, liso.

Distribución. Costa Rica, Colombia, Venezuela, Perú, Brasil Guiana. En Costa Rica se conoce en los bosques muy húmedos de la vertiente atlántica, en las llanuras de Tortuguero y en la cordillera de Talamanca, 50-400 m de elevación.

Fenología. Flores no observadas; frutos en febrero y octubre.

Dichapetalum rugosum se caracteriza por hábito trepador o al menos subescandente, estípulas deciduas y enteras, hojas rugosas, láminas con el envés pubescente, inflorescencias peciolares y grandes frutos tomentulosos, con 2-3 depresiones longitudinales que le dan una apariencia angulada, con pericarpo leñoso.

En Costa Rica, la única especie que presenta al mismo tiempo los caracteres de hábito escandente, estípulas enteras y deciduas y frutos oblongo-obovados a oblongo-elipsoides, con 2-3 depresiones longitudinales, es $D$. odoratum. Sin embargo, esta última tiene hojas más estrechas, glabradas con la edad, tallitos más lenticelados y se encuentra a mayor elevación.

Especímenes examinados. Costa Rica. Heredia: Sarapiquí, Horquetas, Río San Rafael, $10^{\circ} 20^{\prime} \mathrm{N}$,

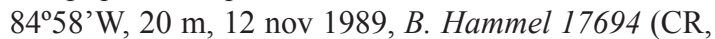
MO); Sarapiquí, Puerto Viejo, E.B. La Selva, camino a la estación del río, $10^{\circ} 26^{\prime} \mathrm{N}, 84^{\circ} 01^{\prime} \mathrm{W}, 50 \mathrm{~m}$, oct 2003 , R. Kriebel 4004 (CR, INB, MO). Limón: Talamanca, Fila Matama, La Bomba, Aguas arriba del Río Banano, Fila Asunción, $9^{\circ} 54^{\prime} \mathrm{N}, 83^{\circ} 12^{\prime} \mathrm{W}, 400$ m, 20 febr 1995 , A. Rodríguez 572 (CR, INB, MO).

Agradecimientos. Los autores desean agradecer a Claudia Aragón, por las ilustraciones, así como a Carlos Morales por sus observaciones y la ayuda en las diagnosis latinas.

\section{LiTERATURA CITADA}

Prance, G.T. 1972. Dichapetalaceae. Fl. Neotrop. Monogr. 10: 1-84.

Prance, G.T. 1977. Two new species for the flora of Panamá. Brittonia 29(2): 156-158.

Prance, G.T. 1979. A new species of Dichapetalum from Suriname. Bull. Torrey Bot. Club 106: 309312 .

Prance, G.T. 1994. Four new species of neotropical Dichapetalaceae. Kew Bull. 49: 129-136. 
Prance, G.T. 1996. Additions to Neotropical

Dichapetalum. Kew Bull. 50: 213-219.

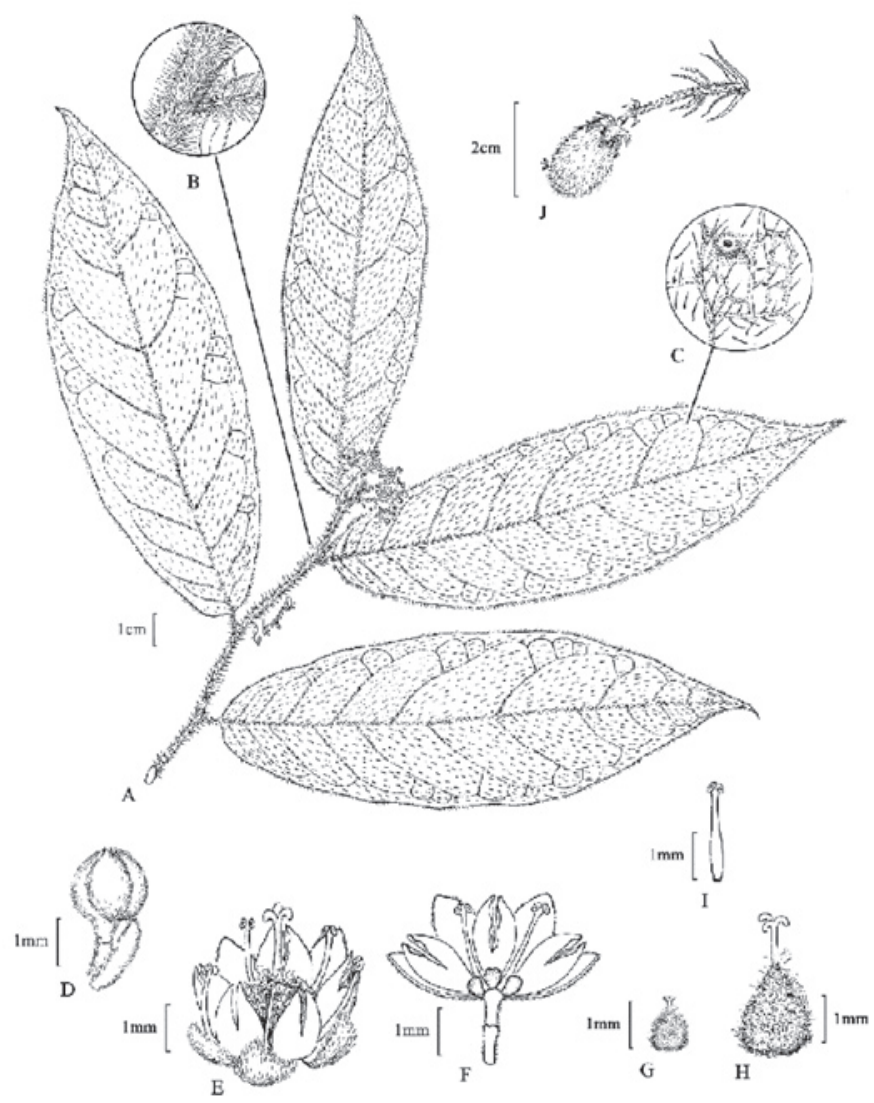

Fig. 2. Dichapetalum reliquum Kriebel \& Al. Rodr. (Kriebel \& Rodríguez 3419). - A. Hábito. - B. Estípula. - C. Glándula en el envés de la hoja. - D. Botón floral. - E. Flor hermafrodita. - F. Corte longitudinal de flor hermafrodita. - G. Ovario de flor masculina. - H. Ovario de flor hermafrodita. - I. Estambre. - J. Fruto. 